Editorial

\title{
COVID-I 9 pandemic and future burden of chronic liver diseases
}

Keywords: cytokine release syndrome, COVID-19, ALP, GGT, renin-angiotensin-aldosterone, direct acting agents

Abbreviations: ACE2, angiotensin-converting enzyme 2; CRS, cytokine release syndrome; RAS, renin-angiotensin-aldosterone system; CLD, chronic liver disease; DAA, direct acting agents

\section{Editorial}

In the last 2 years, the world experienced COVID-19 pandemic as the most challenging infectious disease of the 21 st century. ${ }^{1} \mathrm{Up}$ to April, 2021, there were 141 million positive cases and 3million deaths worldwide and the virus affects both humans and animals. ${ }^{2,3}$ This virus enter into human cells via angiotensin-converting enzyme 2 (ACE2) receptor which express in many organs including cholangiocytes. 4,5 The increased expression of viral mRNA has confirmed in the infected human liver ductal organoids and biomarkers of cholangiocyte injury including ALP and GGT, have been shown to be elevated in some COVID-19 patients with liver dysfunction. ${ }^{6}$

Whether SARS-CoV-2 can directly target the liver, specifically hepatocytes, is unknown and reports on a limited number of liver biopsy samples from COVID-19 patients showed moderate microvesicular steatosis, slightly watery degeneration or necrosis of hepatocytes, mild sinusoidal dilatation, and lymphocytic endotheliitis, indicating the liver injury might be caused by SARS-CoV-2 infection. ${ }^{7,8}$ SARSCoV2 viral load has been tested in about $48 \%$ of cases with negative respiratory samples and viral nucleocapsid was detected in the cytoplasm of intestinal biopsies, which indicated that viruses could enter the portal circulation to reach the liver., ${ }^{910}$ Sub-optimal antibody activity cannot completely eliminate the virus and leads to persistent viral replication and inflammation, ${ }^{11}$ Cytokine release syndrome (CRS) and renin-angiotensin-aldosterone system (RAS) activation. ${ }^{12}$

These findings indicate that the crosstalk between hyper inflammation and dysregulated immune responses is involved in COVID-19-associated liver injury. ${ }^{13}$ Abnormal coagulation process, derangement of blood circulation or endothelial damage, hepatic ischemia/hypoxia-reperfusion injury may be one of the possible mechanisms of liver injury in COVID-19..$^{10,14,15}$ The detrimental effects and liver injury mainly related to certain medications used during hospitalization has been proved and these drugs should be given with caution. ${ }^{16,17}$ Preliminary data indicate $2-11 \%$ of patients with COVID-19 had pre-existing chronic liver disease (CLD) and 14-53\% with COVID-19 developed hepatic dysfunction, particularly in severe COVID-19. ${ }^{18,19}$ The other side of the coin is sedentary life style during social limitations due to COVID pandemic which can further exacerbate liver damage caused by overweight, less activity and nonalcoholic fatty liver syndrome (NAFLD). ${ }^{20,21}$ Among 3 major chronic liver diseases include hepatitis B, Hepatitis C and NAFLD, currently Hepatitis B is potentially preventable by active and passive immunization and introduction of direct acting agents (DAA) against Hepatitis C, theoretically has changed this virus to an eradicable one. So it is imaginable that in the next decade, our major problem in the field of hepatology would be challenging with NAFLD and its potential complication, liver cirrhosis.
Volume 12 Issue 3 - 202 I

\author{
Pezhman Alavinejad, Tahmineh Farbod Ara \\ Department of Gastroenterology and Hepatology, Ahvaz \\ Jundishapur University of Medical sciences, Iran
}

Correspondence: Pezhman Alavinejad, Associate professor of Gastroenterology and Hepatology, Ahvaz Jundishapur University of medical sciences, Ahvaz, Iran, Tel, 00989 I6I I I5880, Email pezhmanalavinejad@gmail.com

Received: Aprill 26, 2021 | Published: May 24, 2021

Thus, the interaction between local liver injury caused by direct cytopathic effects of SARS-CoV-2 and systemic disturbances from one side and burden of sedentary life style and fatty liver needs to be further investigated and we should be aware of potential risk factors for liver function to prevent a probable next pandemic cause by fatty liver. In this regard WHO in 2021, pertained World Digestive Health Day by Raising Awareness of Obesity to further warns and highlights the importance of potential upcoming pandemic by sedentary life style and fatty liver disease.

\section{Acknowledgments}

None.

\section{Conflicts of interest}

Authors declare that we have no conflicting interests.

\section{Funding}

None.

\section{References}

1. Wang Y, Wang Y, Chen Y, et al. Unique epidemiological and clinical features of the emerging 2019 novel coronavirus pneumonia (COVID-19) implicate special control measures. J Med Virol. 2020;92(6):568-576.

2. Cascella M, Rajnik M, Cuomo A, Dulebohn SC, Di Napoli R. Features, evaluation, and treatment of coronavirus (COVID-19). StatPearls. 2021.

3. Gorbalenya AE, Baker SC, Baric R, et al. Severe acute respiratory syndrome-related coronavirus: The species and its viruses-a statement of the Coronavirus Study Group. Nature Microbiology. 2020;5:536-544.

4. Zou X, Chen K, Zou J, et al. Single-cell RNA-seq data analysis on the receptor ACE2 expression reveals the potential risk of different human organs vulnerable to 2019-nCoV infection. Front Med. 2020;14(2):185192.

5. Zhao B, Ni C, Gao R, et al. Recapitulation of SARS-CoV-2 infection and cholangiocyte damage with human liver ductal organoids. Protein Cell. 2020;11(10):771-775. 
6. Cai Q, Huang D, Yu H, et al. COVID-19: abnormal liver function tests. $J$ Hepatol. 2020;73(3):566-574.

7. Sonzogni A, Previtali G, Seghezzi M, et al. Liver histopathology in severe COVID 19 respiratory failure is suggestive of vascular alterations. Liver International. 2020;40(9):2110-2116.

8. Xu Z, Shi L, Wang Y, et al. Pathological findings of COVID-19 associated with acute respiratory distress syndrome. Lancet Respir Med. 2020;8(4):420-422.

9. Pirola CJ, Sookoian S. SARS-CoV-2 virus and liver expression of host receptors: Putative mechanisms of liver involvement in COVID-19. Liver International. 2020;40(8):2038-2040.

10. Bertolini A, van de Peppel IP, Bodewes FA, et al. Abnormal liver function tests in patients with COVID-19: Relevance and potential pathogenesis. Hepatology. 2020;72(5):1864-1872.

11. Fu Y, Cheng Y, Wu Y. Understanding SARS-CoV-2-mediated inflammatory responses: from mechanisms to potential therapeutic tools. Virol Sin. 2020 Jun;35(3):266-271.

12. Li D, Ding X, Xie M, et al. COVID-19-associated liver injury: from bedside to bench. $J$ Gastroenterol. 2021;56(3):218-230.

13. Chen $\mathrm{G}, \mathrm{Wu} \mathrm{DI}$, Guo W, et al. Clinical and immunological features of severe and moderate coronavirus disease 2019. J Clin Invest. 2020;130(5):2620-2629.
14. Duarte-Neto AN, Monteiro RA, da Silva LF, et al. Pulmonary and systemic involvement in COVID-19 patients assessed with ultrasoundguided minimally invasive autopsy. Histopathology. 2020;77(2):186-197.

15. Zhai Y, Petrowsky H, Hong JC, et al. Ischaemia-reperfusion injury in liver transplantation-from bench to bedside. Nat Rev Gastroenterol Hepatol. 2013;10(2):79-89.

16. Fan Z, Chen L, Li J, et al. Clinical features of COVID-19-related liver functional abnormality. Clin Gastroenterol Hepatol. 2020;18(7):15611566 .

17. Cai Q, Huang D, Yu H, et al. COVID-19: abnormal liver function tests. $J$ Hepatol. 2020;73(3):566-574.

18. Li D, Ding X, Xie M, et al. COVID-19-associated liver injury: from bedside to bench. J Gastroenterol. 2021;56(3):218-230.

19. Jothimani D, Venugopal R, Abedin MF, et al. COVID-19 and Liver. $J$ Hepatol. 2020;73(5):1231-1240.

20. Romero-Blanco C, Rodríguez-Almagro J, Onieva-Zafra MD, et al. Physical activity and sedentary lifestyle in university students: Changes during confinement due to the Covid-19 pandemic. Int J Environ Res Public Health. 2020;17(18):6567.

21. Pérez-Rodrigo C, Gianzo Citores M, Hervás Bárbara G, et al. Patterns of change in dietary habits and physical activity during lockdown in Spain due to the COVID-19 pandemic. Nutrients. 2021;13(2):300. 